\title{
Farinha de resíduos da filetagem de tilápia em rações para alevinos de tilápia do Nilo (Oreochromis niloticus)
}

\section{Tilapia by-product meal in rations for Nile tilapia (Oreochromis niloticus) fingerlings}

\author{
Aldi Feiden ${ }^{1 *}$; Wilson R. Boscolo²; Altevir Signor ${ }^{3}$; \\ Arcangelo A. Signor ${ }^{4}$; Adilson Reidel ${ }^{5}$
}

Resumo

\begin{abstract}
Objetivando avaliar a inclusão de farinha de resíduos da filetagem de tilápias (FT) na alimentação de alevinos de tilápia do Nilo (Oreochromis niloticus), foram utilizados 125 alevinos de tilápia do Nilo com peso inicial médio de $0,72 \pm 0,19 \mathrm{~g}$, distribuídos em um delineamento inteiramente casualizado com cinco tratamentos e cinco repetições, em 25 aquários (30L cada). As rações foram formuladas de forma a conterem $0,5,10,15 \%$ de FT e $0 \%$ de FT mais metionina (0+met), sendo as mesmas isoenergéticas isoprotéicas, isocalcíticas e isofosfóricas. Após 28 dias de experimento foram avaliados as médias de peso final (PF), ganho de peso (GP), conversão alimentar aparente (CA) e sobrevivência (SO). Não foram observadas diferenças $(\mathrm{P}>0,05)$ entre os parâmetros avaliados. Conclui-se que a FT pode ser utilizada em até $15 \%$ em substituição ao farelo de soja em rações para alevinos de tilápia sem causar prejuízo ao seu desempenho.
\end{abstract}

Palavras-chave: Farinha de resíduos de tilápia, Oreochromis niloticus, desempenho, nutrição de peixes

Abstract

Objectifying to evaluate the inclusion of tilapia processing residues (FT) in the feeding of Nile tilapia (Oreochromis niloticus) fingerlings, 125 Nile tilapia fingerlings (with average initial weight of $0.72 \pm 0.19 \mathrm{~g}$ ) were distributed in a completely randomized design with five treatments and five repetitions in 25 aquariums (30L). The rations were formulated to contain $0,5,10,15 \%$ of FT and $0 \%$ FT plus methionine $(0+$ met). Isoproteics, isocalcitics, isophosphorics and isoenergetics diets were used. After 28 days of experiment, final weight (PF), weight gain (GP), feed conversion ratio (CA) and survival (SO), were evaluated. No differences were observed $(\mathrm{P}>0.05)$ for the studied parameters. It was concluded that the FT can be used up to $15 \%$ in substitution to the soybean meal in the diet of nile tilapia fingerlings.

Key words: Tilapia by-product meal, Oreocromis niloticus, performance, fish nutrition

1 Professor Adjunto da Universidade Estadual do Oeste do Paraná, UNIOESTE, Campus Toledo. E-mail- aldi@unioeste.br

2 Professor Adjunto da Universidade Estadual do Oeste do Paraná, UNIOESTE, Campus Toledo. E-mail-wrbposcol@unioeste.br

3 Engenheiro de Pesca, Mestrando, UNESP/Jaboticabal São Paulo. E-mail- altevirsignor@bol.com.br

4 Acadêmico do Curso de Engenharia de Pesca, Universidade Estadual do Oeste do Paraná, UNIOESTE, Campus Toledo. E-mailaasignor@pop.com.br

5 Engenheiro de Pesca - Doutorando, UNESP/Jaboticabal São Paulo. E-mail- reidel@unioeste.br

* Autor para correspondência. 


\section{Introdução}

Entre as espécies de peixes cultivadas o grupo das tilápias é o segundo em volume de produção no mundo (ALCESTE; JORY, 1998; LOVSHIN, 1998; NAYLOR et al., 2000), e a terceira em geração de renda (BORGHETTI; OSTRENSKY; BORGHETTI, 2003), e apresenta rusticidade ao manejo (BOSCOLO; HAYASHI; MEURER, 2002), fácil manipulação de sexo, crescimento rápido e carne de ótima qualidade (BOSCOLO, 2003a). É uma espécie apropriada para a indústria de filetagem, tendo ampla aceitação pelo mercado consumidor pela inexistência de espinhos em forma de "Y" no seu filé (HILDSORF, 1995), tornando-se uma espécie de grande interesse para a piscicultura.

Entre as espécies de maior interesse comercial destacam-se a tilápia do Nilo (Oreochromis niloticus), a tilápia de Mossambique (Oreochromis mossambicus), a tilápia azul (Oreochromis aureus), Oreochromis machrochir, Oreochromis hornorum, Oreochromis galilaeus, Tilapia zilli e Tilapia rendalli (EL-SAYED, 1999). O principal produto da industrialização da tilápia é o filé, e os resíduos do processamento representam cerca de 60 a $70 \%$ da matéria prima utilizada (BOSCOLO et al., 2001a), que geralmente são descartados pelas indústrias de filetagem, pelo desconhecimento de seu potencial como alimento para produção animal, tornando-se um potencial poluidor (BOSCOLO, 2003a). Os resíduos obtidos da pesca e da indústria de processamento do pescado apresentam potencial para serem utilizados na aquicultura desde que processados corretamente (BOSCOLO, 2003a; ELSAYED, 1998; EL-SAYED, 1999; ESPE et al., 1999; KOTZAMANIS et al., 2001; MURRAY et al., 2003).

$\mathrm{O}$ crescimento e a intensificação da aquicultura tem aumentado a demanda por ingredientes de qualidade para utilização na formulação de rações. Este fato aliado à menor disponibilidade mundial de farinha de peixe e seu elevado custo (BOSCOLO, 2003a) leva à necessidade de se pesquisar fontes protéicas alternativas de boa qualidade (EL-SAYED, 1999; NENGAS; ALEXIS; DAVIES, 1999; SUGIURA et al., 2000), que proporcionem o melhor desempenho com o menor custo, o que é fundamental para o sucesso da atividade. A substituição de fontes tradicionais de proteína por alimentos alternativos que possam fornecer proteína a baixo custo, é muito importante para a cadeia produtiva de pescado (BOSCOLO et al., 2004; LOWELL, 1989; MEURER; HAYASHI; BOSCOLO, 2003a; MEURER; HAYASHI; BOSCOLO, 2003b), e a utilização de resíduos industriais pode proporcionar outra fonte de agregação de valor à indústria de processamento.

A inclusão de farinha de resíduos em dietas para peixes é limitada pelo seu alto teor de cinzas (BOSCOLO et al., 2003b; MILLAMENA, 2002), podendo resultar, quando incluída em altas concentrações, em altos teores de fósforos e cálcio na dieta e consequente eutrofização do meio ambiente (BOSCOLO, 2003a; HARDY, 1996; SUGIURA et al., 2000). Boscolo (2003a) avaliando a digestibilidade de farinha de resíduos da industria de filetagem de tilápias concluiu que é um alimento protéico de boa qualidade e com potencial para a inclusão em rações pois apresenta boa disponibilidade de nutrientes.

A suplementação de metionina em rações onde a principal fonte protéica é o farelo de soja, é necessária para a tilápia do Nilo (FURUYA, 2000; BOSCOLO et al., 2001a; BOSCOLO, 2003a). Aminoácidos livres puríficados são adicionados na dieta de peixes visando suplementar os aminoácidos deficientes, proporcionando um melhor balanceamento dos nutrientes disponíveis na dieta.

O presente trabalho teve como objetivo avaliar a inclusão da farinha de resíduos da filetagem de tilápia e a utilização de metionina sintética sobre o desempenho e sobrevivência de alevinos de tilápia do Nilo.

\section{Materiais e Métodos}

O presente experimento foi realizado no Laboratório de Aqüicultura da Universidade Estadual do Oeste do Paraná- Campus Toledo no período de 
26/11 à 24/12/03. Foram utilizados 125 alevinos de tilápia do Nilo apresentando peso e comprimento inicial médio de $0,72 \pm 0,19 \mathrm{~g}$ e $3,49 \pm 0,29 \mathrm{~cm}$, respectivamente, distribuídos em um delineamento experimental inteiramente casualizado com cinco tratamentos e cinco repetições, sendo a unidade experimental considerada como um aquário com cinco alevinos. Foram utilizados 25 aquários com capacidade de 30L, dotados de aeração constante através de um sistema conectado a um soprador de ar central.

Os valores médios da composição bromatológica (MS, PB, EB, EE, MM, Ca, P) da farinha de resíduos de filetagem de tilápias estão apresentadas na Tabela 1.

Tabela 1. Valores médios da composição bromatológica da farinha de resíduos da indústria de filetagem de tilápias (matéria natural).

\begin{tabular}{lc}
\hline Nutrientes & $(\%)$ \\
\hline Matéria seca $^{1}$ & 94,10 \\
Proteína bruta $^{1}$ & 50,37 \\
${\text { Energia bruta }(\mathrm{kcal} / \mathrm{kg})^{2}}^{1}$ & 4483,09 \\
Extrato etéreo $^{1}$ & 21,77 \\
Matéria mineral $^{1}$ & 18,75 \\
Cálcio $^{3}$ & 7,87 \\
Fósforo $^{3}$ & 2,78 \\
\hline
\end{tabular}

Fonte: extraída de Boscolo (2003a)

${ }^{1}$ Análises realizadas no Laboratório de Tecnologia do Pescado/UNIOESTE.

${ }^{2}$ Análise realizada no Laboratório de Alimentos LANA/ DZO/UEM

${ }^{3}$ Análises realizadas no Laboratório de Análises de Solos DAG/UEM.

Para formulação das rações, os alimentos foram moídos em moinho tipo faca com peneira de $0,5 \mathrm{~mm}$ e posteriormente misturados. As rações utilizadas foram formuladas de forma a conterem $0,5,10 \mathrm{e}$ $15 \%$ de farinha de resíduos de tilápia (FT) e $0 \%$ de FT suplementada com metionina, através da inclusão de DL-metionina $99 \%$, sendo as mesmas isoenergéticas (3000 kcal/kg de ED), isoprotéicas (30\% de proteína digestível), isocalcíticas e isofosfóricas (Tabela 2). O nível máximo de inclusão de FT (15\%) foi baseado em Boscolo et al. (2003b), que afirmaram que a exigencia de fósforo para esta espécie era de 0,35 a $0,70 \%$, e portanto, ao se calcular os niveis de inclusão de FT, verificou-se que $15 \%$ (FT) na ração atendia as exigências de fósforo total. $\mathrm{O}$ arraçoamento foi realizado com uma quantidade equivalente a $10 \%$ da biomassa, quatro vezes ao dia, às 8:00, 11:00, 14:00 e 17:00h, com biometrias semanais para a correção da ração a ser fornecida.

Tabela 2: Composição percentual e química das rações utilizadas na dieta de alevinos de tilápia do Nilo (Oreochromis niloticus).

\begin{tabular}{|c|c|c|c|c|c|}
\hline \multirow[b]{2}{*}{ Ingredientes } & \multicolumn{5}{|c|}{ Inclusão de Farinha de resíduos de filetagem de tilápia (\%) } \\
\hline & 0 & 5 & 10 & 15 & $(0 \% \mathrm{FT}+\mathrm{Met})$ \\
\hline Antioxidante (BHT) & 0,02 & 0,02 & 0,02 & 0,02 & 0,02 \\
\hline Calcário calcítico & 2,00 & 1,33 & 0,67 & 0,00 & 2,00 \\
\hline DL-metionina & 0,00 & 0,00 & 0,00 & 0,00 & 0,08 \\
\hline Fosfato bicálcico & 1,8 & 1,20 & 0,60 & 0,00 & 1,80 \\
\hline Farelo de soja & 64,51 & 58,22 & 51,93 & 45,65 & 64,50 \\
\hline Earinha de resíduos de tilápia & 0,00 & 5,00 & 10,00 & 15,00 & 0,00 \\
\hline Farelo de trigo & 14,30 & 16,79 & 19,26 & 21,73 & 14,25 \\
\hline Milho & 12,00 & 13,37 & 14,74 & 16,10 & 11,99 \\
\hline Óleo de soja & 3,87 & 2,58 & 1,29 & 0,00 & 3,87 \\
\hline Suplemento (min. + vit. $\left.{ }^{1}\right)$ & 1,00 & 1,00 & 1,00 & 1,00 & 1,00 \\
\hline Sal & 0,50 & 0,50 & 0,50 & 0,50 & 0,50 \\
\hline Total & 100,00 & 100,00 & 100,00 & 100,00 & 100,00 \\
\hline \multicolumn{6}{|l|}{ Nutrientes (\%) } \\
\hline Energia digestível (kcal/kg) & $3.069,41$ & $3.069,18$ & $3.068,94$ & $3.068,70$ & 3067,24 \\
\hline Proteina bruta & 33,52 & 33,54 & 33,554 & 33,573 & 33,547 \\
\hline Extrato etéreo & 5,62 & 5,47 & 5,33 & 5,16 & 5,62 \\
\hline Fibra & 5,33 & 5,21 & 5,09 & 4,96 & 5,33 \\
\hline Amido & 20,45 & 21,19 & 21,93 & 22,67 & 20,42 \\
\hline Fosfato total & 0,88 & 0,89 & 0,91 & 0,93 & 0,88 \\
\hline Calcio & 1,32 & 1,319 & 1,32 & 1,32 & 1,32 \\
\hline Linolêico & 3,10 & 2,33 & 1,65 & 0,98 & 3,00 \\
\hline Lisina & 1,91 & 1,91 & 1,91 & 1,91 & 1,91 \\
\hline Metionina & 0,47 & 0,50 & 0,52 & 0,55 & 0,55 \\
\hline Metionina + Cistina & 1,14 & 1,16 & 1,17 & 1,19 & 1,21 \\
\hline
\end{tabular}

${ }^{1}$ Níveis de garantia por quilograma do produto (Rovimix peixes): Vit. A, 500.000UI; Vit. D, 200.000UI; Vit. E, 5.000mg; Vit. K3, 1.000mg; Vit. B1, 1.500mg; Vit. B2, 1.500mg; Vit. B6, 1.500mg; Vit. B12, 4.000mg; Ác. Fólico, 500mg; Pantotenato Ca, 4.000mg; Vit. C, 15.000mg; Biotina, 50mg; Inositol, 10.000; Nicotinamida, 7.000; Colina, 40.000mg; Co, 10mg; $\mathrm{Cu}$, 500mg; Fe, 5.000mg; I, 50mg; Mn, 1500mg; Se, 10mg; $\mathrm{Zn}, 5.000 \mathrm{mg}$.

${ }^{2}$ Baseados nos valores de energia e proteína digestível proposto por Boscolo et al. (2002) e Boscolo (2003).

Diariamente foi realizada a sifonagem do fundo dos aquários às 8:00 e 17:00h, antes da primeira e última alimentação, respectivamente, substituindo-se cerca de $50 \%$ do volume total de água por vez. Os 
parâmetros físico-químicos como $\mathrm{pH}$, condutividade $(\mathrm{mS} / \mathrm{cm})$, e oxigênio dissolvido $(\mathrm{mg} / \mathrm{L})$, foram medidos semanalmente, enquanto que a temperatura foi monitorada diariamente as 8:00 e as 17:00 h.

Ao final do experimento os animais de cada unidade experimental foram pesados e medidos para avaliação do peso final médio (PF), ganho de peso médio (GP), conversão alimentar aparente (CA) e sobrevivência (SO). O fator de condição foi obtido através da expressão ( $\left.w t / 1 t^{3} \times 100\right)$, sendo $w t=$ peso total e lt = comprimento total, conforme descrito por Vazzoler e Vazzoler (1965).

Os dados obtidos foram submetidos a análise de variância a nível de 5\% de significância através do programa estatístico SAEG (Sistema de Análises Estatísticas e Genéticas) UFV, (1997).

\section{Resultados e discussões}

Os valores médios de temperatura, condutividade elétrica da água, oxigênio dissolvido e $\mathrm{pH}$ durante o período experimental foram de $26,99 \pm 1,13^{\circ} \mathrm{C}$; $126 \pm 8,09 \mathrm{mS} / \mathrm{cm} ; 6,54 \pm 0,58 \mathrm{mg} / \mathrm{L} ; 7,76 \pm 0,15$, respectivamente, e permaneceram dentro da faixa ideal para o desenvolvimento de peixes (BOYD, 1990).

Os resultados de desempenho (Tabela 3) não apresentam diferenças $(\mathrm{P}>0,05)$ para $\mathrm{PF}, \mathrm{CF}, \mathrm{GP}$, $\mathrm{CA}, \mathrm{SO}$ e FC, dos animais alimentados com inclusão de diferentes níveis de FT na ração e metionina sintética.

Os resultados obtidos concordam com os de Boscolo (2003a), que avaliando a inclusão de FT (0, $5,10,15$ e 20\%) na dieta de larvas de tilápia do Nilo não observou diferenças no desempenho e sobrevivência dos peixes em função dos diferentes níveis de inclusão de FT. Mas avaliando a inclusão de FT $(0,6,76$ e $13,55 \%$ de FT) em rações para alevinos de tilápia do Nilo observou melhora no desenvolvimento dos animais com a inclusão de FT concluindo que $6,76 \%$ de FT supre a necessidade de metionina e $13,55 \%$ supriu a exigência de fósforo.

Tabela 3: Desempenho de alevinos de tilápia do Nilo submetidos a diferentes níveis de inclusão de farinha de resíduos de filetagem de tiápias.

\begin{tabular}{lcccccc}
\hline & \multicolumn{5}{c}{ Inclusão de farinha de resíduos de tilápia (FT) e metionina (met) } \\
\cline { 2 - 7 } Parâmetros & 0 & 5 & 10 & 15 & $0+$ met & CV \\
\hline Peso inicial médio & 0,74 & 0,74 & 0,74 & 0,74 & 0,74 & 1,53 \\
Peso final médio & 2,89 & 4,04 & 3,04 & 3,20 & 2,36 & 27,81 \\
Ganho de peso médio & 2,15 & 3,30 & 2,30 & 2,46 & 1,62 & 36,37 \\
Conversão alimentar aparente & 1,38 & 1,14 & 1,54 & 1,38 & 1,50 & 28,59 \\
Sobrevivência & 96 & 92 & 88 & 92 & 92 & 16,56 \\
Fator de condição & 2,04 & 1,92 & 2,00 & 1,97 & 1,98 & 9,66 \\
\hline
\end{tabular}

Tratamentos: $0=$ sem inclusão de FT; $5=5 \%$ de inclusão de FT; $10=10 \%$ de inclusão de FT; $15=15 \%$ de inclusão de FT; $0+$ met $=0 \%$ de FT com inclusão de metionina sintética.

Os resultados obtidos no atual experimento também estão de acordo com os de El-Sayed (1998), que avaliando farinha de resíduos da industrialização de camarão em substituição a farinha de peixe para tilápias vermelhas (O. niloticus X $O$. hornorum) na fase inicial, observou melhoria no desenvolvimento dos peixes com a inclusão destes resíduos. Toledo et al. (1987 apud EL-SAYED, 1999), também indicaram que a farinha da cabeça de camarão pode ser incluído em até $15 \%$ da dieta para tilápia azul.

Signor et al. (2004) observaram diferenças no desempenho de piavuçú (Leporinus macrocephalus), alimentados com diferentes níveis de FT $(0,5,10$ e $15 \%$ de FT e $0 \%$ de FT suplementado com metionina), com melhores resultados obtidos nos tratamentos com inclusão de FT e suplementação de metionina sintética, 
demonstrando que a FT promove melhor desempenho dos peixes quando adicionados na dieta. Kotzamanis et al., (2001), observaram resultados semelhantes utilizando resíduos da industrialização de trutas (visceras, pele, cabeças e ossos) na alimentação do "gilthead bream" substituindo aproximadamente $20 \%$ da farinha de peixe. Estes resultados corroboram com os de Viana et al. (1996) os quais concluíram que os resíduos da industrialização do Abalone "Haliotis fulgens" é uma fonte alimentar importante, pois além de não causar prejuizo no desempenho dos animais, a sua utilização em rações é uma potencial solução ao seu aproveitamento.

Não foi observado diferença $(\mathrm{P}>0,05)$ na $\mathrm{CA}$ entre os tratamentos. Por outro lado, Signor et al. (2004) utilizando FT na dieta de piavuçú observaram melhoria na conversão alimentar em peixes alimentados com níveis crescentes de inclusão de FT na dieta. O tratamento com $0 \%$ de FT suplementado com metionina apresentou resultado superior com relação a ração controle (à base de milho e farelo de soja), indicando que estes peixes aproveitam bem este alimento como fonte protéica e também a metionina sintética. Os alimentos utilizados na formulação de rações para peixes com altos índices protéicos de origem animal são dispensáveis como atractantes em alevinos de tilápia (BOSCOLO et al., 2001b), porém são utilizados na dieta de peixes quando encontrados a preços acessíveis, sendo que muitos apresentam alta disponibilidade de nutrientes (HAYASHI et al., 2002), podendo melhorar seu desempenho, diminuindo os custos de produção, com uma menor taxa de conversão alimentar.

Segundo NRC (1993), deve ser incluído no mínimo $0,75 \%$ de metionina total em dieta para tilápia do Nilo. Em rações onde a principal fonte protéica é o farelo de soja é necessária a inclusão de metionina sintética para tilápia do Nilo (FURUYA, 2000), devido a suas características nutricionais (BOSCOLO et al., 2001a; BOSCOLO, 2003a). Aminoácidos livres puríficados são adicionados em dieta de peixes visando suplementar os aminoácidos deficientes, embora trabalhos demonstrem que muitas espécies como Truta arco-íris (KAUSHIK; LUQUET, 1980; RUNSEY; KETOLA, 1975), Cyprinus carpio (AOE et al., 1970; PONGMANEERAT et al., 1993), e tilápia (MAZID et al., 1978; VIOLA; ANGEONI; LAHAV, 1994), não apresentam utilização eficiente dos aminoácidos livres purificados (RONNESTAD et al., 2000).

O estágio de desenvolvimento do trato digestório influencia na forma como são utilizados os aminoácidos livres na dieta, e isto pode ser explicado devido a rápida absorção dos aminoácidos livres purificados, podendo resultar em catabolismo aminoacídico reduzindo a eficiência de sua utilização (LOVELL, 1991). Li; Robinson (1998) suplementando lisina e metionina sintética ou a combinação destas na dieta do bagre do canal, observaram restrição alimentar e menor ganho de peso, semelhante a dietas com deficência protéica, concluíndo que o excesso de aminoácido era utilizado como energia e não para síntese protéica, não ocorrendo o incremento em peso.

A FT se apresenta como importante alimento para ser utilizado na alimentação de peixes, pois além de seu baixo custo não apresenta prejuízo no desenvolvimento dos animais, e proporciona a formulação de rações práticas, ou seja, sem a suplementação de fósforo com fosfato bicálcico (Tabela 1).

\section{Conclusão}

Neste experimento a farinha de resíduos da industrialização de tilápias pode ser utilizada em até $15 \%$ de inclusão em rações para alevinos de tilápia do Nilo, não causando prejuízo no desempenho dos animais. A suplementação de metionina sintética não se mostrou eficiente para alevinos de tilápia do Nilo, demostrando que a FT atende às suas exigências.

\section{Agradecimentos}

Agradecemos a indústria de processamento de pescado Frigopisces de Assis Chateaubriand, pelo fornecimento da farinha de resíduos de filetagem de tilápias. 


\section{Referências}

ALCESTE, C.; JORY, D. E. Análisis de las tendencias actuales en la comercialización de tilapia en los Estados Unidos de Norteamérica y la Unión Europea. In: CONGRESSO SUL-AMERICANO DE AQUICULTURA, 1., 1998, Recife. Anais... Recife: SIMBRAq, 1998. p. 349364.

AOE, H.; MASUDA, I.; ABE, I.; SAITO, T.; TOYODA, T.; KITAMURA, S. Nutrition of protein in young carp: I. Nutritive value of free amino acids. Bulletin of the Japanese Society of Scientific Fisheries. Tokyo, 36, p. 407-413, 1970.

BORGHETTI, N. R. B.; OSTRENSKY, A.; BORGHETTI, J. R. Aqüicultura: Uma visão geral sobre a produção de organismos aquáticos no Brasil e no mundo. Curitiba: Grupo Integrado de Aqüicultura e Estudos Ambientais, 2003. 128 p.

BOSCOLO, W. R.; HAYASHI, C.; MEURER, F. Digestibilidade Aparente da Energia e Nutrientes de Alimentos Convencionais e Alternativos para a Tilápia do Nilo (Oreochromis niloticus, L.). Revista Brasileira de Zootecnia, Viçosa, v. 13, n. 2, p. 539-545, 2002.

BOSCOLO, W. R.; HAYASHI, C.; MEURER, F.; FEIDEN, A.; BOMBARDELLI, R. A. Digestibilidade Aparente da Energia e Proteína das Farinhas de Resíduo da Filetagem da Tilápia do Nilo (Oreochromis niloticus) e da Corvina (Plagioscion squamosissimus) e Farinha Integral do Camarão Canela (Macrobrachium amazonicum) para a Tilápia do Nilo. Revista Brasileira de Zootecnia, Viçosa, v. 33, n. 1, p. 8-13, 2004.

BOSCOLO, W. R. Avaliação de alimentos convencionais e alternativos para tilápias do Nilo. 2000. 78 p. Dissertação (Mestrado em Zootecnia)-Departamento de Zootecnia, Universidade Estadual de Maringá, Maringá, 2000.

BOSCOLO, W. R.. Farinha de resíduos da industria de filetagem de tilápia na alimentação da tilápia do Nilo Oreochromis niloticus. 2003. 83 f. Tese (Doutorado em zootecnia)-Departamento de Zootecnia, Universidade Estadual de Maringá, Maringá, 2003a.

BOSCOLO, W. R.; FEIDEN, A.; REIDEL, A.; BROLL, F. F.; HOLDEFER, A. M.; SANTOS, R. V.; MARANHÃO, T. C. F. Exigência de fósforo da tilápia do Nilo (Oreochromis niloticus) na fase de crescimento. Varia Scientia, Cascavel, v. 03, n. 0,1, p. 115-124, 2003 b.

BOSCOLO, W. R.; HAYASHI, C.; MEURER, F.; SOARES, C. M. Farinhas de peixe, carne e ossos, vísceras e crisálida como atractantes em dietas para alevinos de tilápia do Nilo (Oreochromis niloticus). Revista Brasileira de
Zootecnia, Viçosa, v. 30, n. 5, p. 1397-1402, 2001 b.

BOSCOLO, W. R.; HAYASHI, C.; SOARES, C. M.; FURUYA, W. M.; MEURER, F. Desempenho e características de carcaça de machos revertidos de tilápias do Nilo (Oreochromis niloticus), linhagens tailandesa e comum, nas fases iniciais e de crescimento. Revista Brasileira de Zootecnia, Viçosa, v. 30, n. 5, p. 1391-1396, 2001a.

BOYD, C. Water quality in ponds for aquaculture. London: Birmingham Publishing Co., 1990. 482 p.

EL-SAYED, A. F. M. Alternative dietary protein sources for farmed tilapia. Oreochromis spp. Aquaculture, Amsterdam, v. 179, p. 149-168, 1999.

EL-SAYED, A. F. M. Total replacement of fish meal with animal protein sources in Nile tilapia Oreochromis niloticus (L.) feeds. Aquaculture Research, Oxford, v. 179, n. 4, p. 275-280, 1998.

ESPE, M., SVEIER, H., HOGOY, I.; LIED, E. Nutrient absorption and growth os Atlantic salmon (Salmo salar L.)fed fish protein concentrate. Aquaculture, Amsterdam, v. 174, p. 119-137, 1999.

FURUYA, W. M. Digestibilidade aparente de aminoácidos e substituição da proteína da farinha de peixe pela proteina do farelo de soja com base no conceito de proteína ideal em rações para a tilápia do Nilo (Oreochromis niloticus l.).2000. 69 p. Tese (Doltorado em zootecnia) Universidade Estadual Paulista, Botucatu, 2000.

HARDY, R. W. Alternate protein sources for salmon and trout diets. Animal Feed Science and Technology, Amsterdam, v. 59, p. 71-80,1996.

HAYASHI, C.; BOSCOLO, W. R.; SOARES, C. M.; MEURER, F. Exigência de proteína digestível para larvas de tilápia do Nilo (Oreochromis niloticus) durante a reversão sexual. Revista Brasileira de Zootecnia, Viçosa, v. 31, n. 2, p. 823-828, 2002.

HILDSORF, A. W. S. Genética e cultivo de tilápias vermelhas, uma revisão. Boletim do Instituto de Pesca, São Paulo, v. 22, n. 1, p. 73-78, 1995.

KAUSHIK, S. J.; LUQUET, P. Influence of bacterial protein incorporation and of sulphur amino acid supplementation to such diets on growth of rainbow trout. Aquaculture, Amsterdam, v. 19, n. 2, p. 163-175, 1980.

KOTZAMANIS,Y.P.; ALEXIS,M. N.; ANDRIOPOULOU, A.; CASTRITSI-CATHARIOU, I.; FOTIS, G. Utilization of waste material resulting from trout processing in gilthead bream (Sparus aurata L.) diets. Aquaculture Research, Oxford, v. 32, (suppl.1), p. 288-295, 2001. 
LI, M. H.; ROBINSON, E. H. Effects of supplemental lysine and methionine in low protein diets on weight gain and body composition of young channel catfish Ictalurus punctatus. Aquaculture, Amsterdam, v. 163 p. 297-307, 1998.

LOVELL, R. T. Nutrition of aquaculture species. Journal of Animal Science, Savoy, v. 69, n. 10, p. 4193-4200, 1991.

LOVSHIN, L. L. Red tilapia or Nile tilapia: Which is the best culture fish? In: SIMPÓSIO SOBRE MANEJO E NUTRIÇÃO DE PEIXES, 1998, Piracicaba. Anais... Piracicaba: CBNA, 1998., p. 179-198.

LOWELL, T. Nutiriton and feeding of fish. New York: Van Nostrand Reinhold, 1989.

MAZID, M. A.; TANAKA, Y.; KATAYAMA, T.; SIMPSON, K. L.; CHICHESTER, C. O. Metabolism of amino acids in aquatic animals: III. Indispensable amino acids for Tilapia zillii. Bulletin of the Japanese Society of Scientific Fisheries, Tokyo, v. 44, n. 7, p. 739-742, 1978.

NENGAS, I.; ALEXIS, M. N.; DAVIES, S. J. High inclusion levels of poultry meals and related byproducts in diets for gilthead seabream Sparus auratas L. Aquaculture, Amsterdam, v. 179, p. 13-33. 1999.

MEURER, F.; HAYASHI, C.; BOSCOLO, W. R. Influência do processamento da ração no desempenho e sobrevivência da tilápia do Nilo durante a reversão sexual. Revista Brasileira de Zootecnia, Viçosa, v. 32, n. 2, p. 262-267, 2003a.

MEURER, F.; HAYASHI, C.; BOSCOLO, W. R.. Digestibilidade aparente dos nutrientes e energia de alguns alimentos protéicos para juvenis de tilápia do Nilo (Oreochromis niloticus). Revista Brasileira de Zootecnia, Viçosa, v. 31, n. 2, p. 539-545, 2003 b.

MILLAMENA, O. M. Replacement of fish meal by animal by-product meals in a practical diet for grow-out culture of grouper Epinephelus coiodes. Aquaculture, Amsterdam, v. 204, p. 75-84, 2002.

MURRAY, A. L.; PASCHO, R. J.; ALCORN, S. W.; FAIRGRIEVE, W. T.; SHEARER, K. D.; ROLEY, D. Effects of various feed supplements containing fish protein hydrolysate or fish processing by-products on the innate immune functions of juvenile coho salmon (Oncorhynchus Kisutch).Aquaculture, Amsterdam, v. 220, p. 643-653, 2003.

NATIONAL RESEARCH COUNCIL - NRC. Nutrient requirements of warmwater, fishes and shellfishes: nutrient requirements of domestics animals. Washington, 1993.114 p.
NAYLOR, R. L.; GOLDBURG, R. J.; PRIMAVERA, J. H.; KAUTSKY, N.; BEVERIDGE, M. C. M.; CLAY, J.; FOLKE, C.; LUBCHENCO, J.; MOONEY, H.; TROELL, M. Effect of aquaculture on world fish supplies. Nature, London, v. 405, n. 6790, p. 1017-1024, 2000.

PONGMANEERAT, J.; WATANABE, T.; TAKEUSHI, T.; $\mathrm{SATOH}, \mathrm{S}$. Use of different protein meals as partial or total substitution for fish meal in carp diets. Nippon Suisan Gakkaishi, Tokyo, v. 59, n. 7, p. 1249-1257, 1993.

RONNESTAD, I.; CONCEIÇÃO, L. E. C.; ARAGÃO, C.; DINIS, M. T. Free amino acids are absorbed faster and assimilated more efficiently than protein in postlarval Senegal sole (Solea senegalensis). Journal of Nutrition, Bethesda, v. 130, n. 11, p. 2809-2812, 2000.

RUMSEY, G. L.; KETOLA, H. G. Amino acid supplementation of casein in diets of Atlantic salmon (Salmo salar) fry and of soybean meal for rainbow trout (Salmo gairdneri) fingerlings. Journal of the Fisheries Research Board of Canada, Ottawa, v. 32, n. 3, p. 442-426, 1975.

SIGNOR, A.; FEIDEN, A.; BOSCOLO, W. R.; BOMBARDELLI, R. A.; SIGNOR, A. A.; REIDEL, A. Farinha de resíduo da filetagem de tilápia em rações para alevinos de piauçú Leporinus macrocephalus In: REUNIÃO ANUAL DA SOCIEDADE BRASILEIRA DE ZOOTECNIA, 41., 2004, Campo Grande. Anais... Campo Grande, 2004. 1 CD-ROM.

SUGIURA, S. H.; BABBITT, J. K.; DONG, F. M.; HARDY, R. W. Utilization of fish and animal by-product meals in low-pollution feeds for rainbow trout Oncorhynchus mykiss (Walbaum).Aquaculture Research, Oxford, v. 31, n. 7, p. 585-593, 2000.

UNIVERSIDADE FEDERAL DE VIÇOSA. UFV. SAEG Sistema para análises estatísticas e genéticas: manual do usuário. Viçosa, 1997. 150 p. Versão 7.1.

VAZZOLER, A. E. A..; VAZZOLER, G. Relation between condiction factor and sexual development in Sardinella aurita. Academia Brasileira de Ciências, Rio de Janeiro, v. 37, p. 353-359, 1965.

VIANA, M. T.; LÓPEZ, L. M.; GARCÍA-ESQUIVEL, Z.; MENDEZ, E. The use of silage made from fish and abalone viscera as an ingredient in abalone feed. Aquaculture, Amsterdam, v. 140, p. 87-98, 1996.

VIOLA, S.; ANGEONI, H.; LAHAV, E. Present limits of protein sparing by amino acid supplementation of practical carp and tilapia feeds. Israeli Journal of AquacultureBamidgeh, Nir-David, v. 46, n. 4, p. 203-211, 1994. 
